\section{The effects of a buddy bench on elementary students' solitary behavior during recess}

\author{
Andrew A. Griffin Jr. ${ }^{a}$, Paul Caldarella ${ }^{a, *}$ \\ Christian V. Sabey ${ }^{a}$, Melissa A. Heath ${ }^{a}$
}

\author{
Received: 20 August 2017 \\ Revised: 13 Sept. 2017 \\ Accepted: 15 Sept. 2017 \\ ISSN: 1307-9298 \\ Copyright @ IEJEE \\ www.iejee.com \\ DOI: 10.26822/iejee.2017131884
}

\begin{abstract}
Social skill instruction and school-wide positive behavior support have been found to be effective in treating students with emotional and behavioral disorders. However, students with internalizing behavior are often overlooked for interventions that could improve academic outcomes and prevent problems that might have serious implications, including social withdrawal, social isolation, and suicidal ideation. In this study, a multiple baseline across participants design was used across two elementary school recess playgrounds to evaluate a "buddy bench" intervention, which utilized peers to help socially withdrawn students to decrease social isolation behavior. Students in Grades 1 to 6 were observed during recess. Results revealed that from baseline to intervention phases the number of students engaged in solitary recess behavior decreased between $19 \%$ and $24 \%$. Most students reported positive attitudes towards the intervention, while teachers were more neutral.
\end{abstract}

Keywords: Playground interventions, internalizing behaviors, social isolation, solitary behavior, elementary school

\section{Introduction}

School-wide positive behavior support (SWPBS) can be used to foster a positive learning environment in schools by improving students' social interactions, reducing problem behavior, and addressing emotional and behavioral concerns (Lewis \& Sugai 1999; Sugai \& Horner, 2006; Young, Caldarella, Richardson, \& Young, 2011). The use of simple, cost-effective SWPBS strategies to proactively manage student behavior and improve student outcomes is also emphasized (Cook et al., 2017). A relatively simple intervention referred to as the buddy bench has been used in schools as a positive approach contributing to an inclusive environment in which all students can have friends (Associated Press, 2013; Jorgensen, 2015). While this intervention may benefit all students, its primary focus is on students with or at risk for emotional and behavioral disorders (EBD). In particular, this intervention targets students exhibiting internalizing behaviors by creating an environment where students are more likely to befriend and interact with peers. However, there is no empirical research on this intervention. In this study, we examined the effects of a buddy bench intervention implemented at a Title 1 elementary school to decrease solitary student behavior during recess.

\section{Emotional and Behavioral Disorders}

Students with EBD frequently exhibit problem behaviors classified as either externalizing or internalizing. Externalizing behaviors include acting out and other aggressive and antisocial behaviors. These behaviors are usually disruptive and consequently targeted for interventions (Brumariu, 2010; Merrell \& Gimpel, 1998). Although externalizing behaviors are commonly identified and addressed in schools, less effort has been made to identify and to develop successful interventions for students with internalizing behavior problems (Morris, Shah, \& Morris, 2002; Rubin \& Coplan, 2004).

Internalizing problems include depression, anxiety, obsessive-compulsive disorders, social withdrawal, and somatic symptoms (Brumariu, 2010; Gage, 2013; Merrell \& Gimpel, 1998). Such behaviors often manifest more discretely and receive less attention from school personnel. While few interventions target this population, the performance gap between students with internalizing symptoms and their peers without such symptoms is of concern (Gresham \& Kern, 2004; Kauffman, 2001).

In comparison to other students, those with either externalizing and/or internalizing EBD symptoms

\footnotetext{
a Brigham Young University, Provo, Utah, United States of America. E-mail addresses: (A. A. Griffin) griffinaj13@gmail.com; (P. Caldarella) paul_caldarella@byu.edu; (C. V. Sabey) christian sabey@byu.edu; (M. A. Heath) melissa_allen@byu.edu

* Corresponding author: Paul Caldarella, Brigham Young University, Center for the Improvement of Teacher Education and Schooling, Department of Counseling Psychology and Special Education, MCKB 149D, Provo, Utah, 84606, USA. Email: paul_caldarella@byu.edu
} 
consistently have below average academic performance and graduation rates, less post-school employment success, lower postsecondary enrollment rates, and a greater likelihood of being arrested or involved with the criminal justice system (Fergusson \& Woodward, 2002; Lane, Barton-Arwood, Nelson, \& Wehby, 2008; McCall, 2011). While the general school population has experienced an overall improvement in graduation, employment, and college placement rates, students with EBD have not improved to the same degree as general education students and other special education populations (Wagner, Newman, Cameto, \& Levine, 2005). In comparison to those who graduate from high school, students who drop out earn considerably less money throughout their lifetime. Students with EBD are at a higher risk for dropping out (Jennings, Caldwell, \& Lerner, 2013) and becoming part of these dismal workforce statistics. Additionally, students with internalizing symptoms rarely receive adequate help in transitioning to higher education (McClintick-Greene, 2012).

\section{Typical and Atypical Recess Behavior}

Researchers have examined typical and atypical recess and playground behavior, identifying behaviors that indicate student risk for EBD. Arthur (2004) noted that feeling left out, feeling lonely, spending time in social isolation, and having bad experiences on the recess playground are atypical for elementary age children. Research by Coplan, Ooi, and Rose-Krasnor (2015) also found that solitary behavior on the playground is atypical. In their study, these researchers found that group and dyadic play comprised $89 \%$ of children's play behavior. Furthermore, children in the group-social or average clusters displayed normal social-emotional functioning and reported the lowest levels of anxiety, depression, and loneliness. Children rated as non-social (comprising about $8 \%$ of their sample) had the most extreme socialemotional problems, including social anxiety, depression, and loneliness. Parent ratings also suggested that these children had more peer and emotional problems in comparison to their more social peers.

Coplan and colleagues (2013) found that students engage in solitary playground behavior for different reasons. Some may be alone because they are shy (fear/anxiety related) or prefer being alone (non-fear related), while others feel excluded, rejected or isolated by peers. Additionally, Coplan and colleagues (2015) suggested that different interventions are suited to different types of withdrawn behavior (fear/anxiety related vs. exclusion related). They also noted that students who varied from normal social playground behavior displayed the highest level of internalizing and peer relationship difficulties. They proposed that teachers overseeing recess can effectively identify at-risk students simply by observing those who tend to be alone. Their research is among the first providing evidence that many socially withdrawn students are at-risk students.

\section{Recess Interventions}

Recess, while sometimes viewed as detracting from instruction time, is seen in the SWPBS framework as an invaluable opportunity to improve school climate
(Franzen \& Kamps, 2008). When recess is used effectively, it helps students to develop physically and mentally, improve social skills, and perform better academically (Ginsburg, 2007; Pellegrini \& Bohn, 2005). When utilized purposefully, the time consumed by recess can be viewed as some of most effective minutes of the school day, rather than being judged as lost instruction time.

The use of social skill interventions for students with or at risk for EBD is often implemented as part of SWPBS and can be used to improve student behavior at recess. For example, Marchant et al. (2007) successfully modified students' socially withdrawn recess behavior by using a targeted SWPBS treatment package that included social skill instruction, self-management, and reinforcement for students at risk for internalizing disorders. Marchant and colleagues observed that during recess students improved their communication skills, increased appropriate play, and increased social interaction.

A similar program that has been found to be effective is the Playworks program, evaluated by Bleeker et al. (2012). This program includes structured adult-led recess activities that provide opportunities for student participation. As adult volunteers lead activities at recess, they encourage peer inclusion with group exercise and experience. Bleeker and colleagues found that in schools that incorporated Playworks students were involved in less bullying and exclusionary behavior, and they displayed more on-task behavior during academic instruction and better classroom behavior, than students in non-participating schools. While interventions like Playworks are promising, they are intensive and require coordinating many people (e.g., trained school coordinators, volunteer adults, and other personnel). Many schools lack the resources to run such highly involved interventions.

An alternative recess intervention used by Teerlink, Caldarella, Anderson, Richardson, and Guzman (2017), which did not require extensive resources or the involvement of adult mentors, utilized peer praise notes (PPNs) to encourage and improve appropriate student behavior. Researchers trained students to monitor recess and distribute PPNs to peers they saw displaying behavior that was responsible, respectful, or safe, as outlined by school rules. PPNs were accumulated and later redeemed for motivators. The PPNs appeared to be effective at decreasing office disciplinary referrals (ODRs), improving social relations on the playground, improving student behavior, and increasing the amount of structured play during recess. In an attempt to make the current study simple, efficient, and effective, we also utilized peers in a recess intervention by implementing a buddy bench intervention described below.

\section{Buddy Bench}

The Associated Press (2013) reported that a second grade student, Christian Bucks, from Roundtown Elementary School in Pennsylvania, USA, campaigned for having a buddy bench at his school. This bench, decorated with a special design, was placed in a recess area, and all students were instructed that if they felt lonely they could sit on the bench and someone would be their buddy. 
School administration also instructed all students that if they saw a peer sitting alone at the bench they should befriend and invite the student who was feeling lonely to play. Media outlets have followed and reported on the recent emergence of buddy benches at schools around the United States, and school staff reports that it is an efficient and practical way to help students with social problems (Associated Press, 2013; Jorgensen, 2015). Like other recess interventions, the goal of the buddy bench is to change school climate by structuring part of recess to cue students to interact with and befriend students who might otherwise spend recess alone.

While there is considerable research on social inclusion, only one study mentioning the words buddy bench or friendship bench was identified in the literature. Arthur (2004) conducted a study examining the impact of peerinvolved pro-social interventions at six elementary schools. This researcher tracked the effectiveness of "playground buddies," "buddy benches," "find a friend," "friendship benches," "super-play day," classroom activities, and assembly interventions. Each intervention was intended to help students befriend peers who felt left out. In five out of six schools studied by Arthur, students reported fewer bad experiences and feelings of being left out at post-intervention, as compared to pre-intervention. However, Arthur collected no observational data to verify students' self-report. Due to the limited research on the use of buddy benches, we investigated the use of this intervention to decrease student solitary behavior on the recess playground. We addressed three specific research questions:

1. Was the buddy bench intervention implemented with fidelity?

2. Was the buddy bench intervention effective at decreasing solitary behavior on the playground?

3. Was the buddy bench intervention viewed as socially valid by teachers and students?

\section{Method}

\section{Settings and Participants}

This study took place at an urban Title 1 elementary school in central Utah, USA. Students were in Grades 1 through $6(\mathrm{~N}=388)$. The majority of students, approximately $65 \%$, were non-Caucasian (250 Hispanic, 14 Pacific Islander, 12 American Indian, 9 African-American, 6 Asian); $75 \%$ of the student population received free or reduced price lunch (low SES), and 47\% were English language learners. We selected Grades 1 through 6 because teachers and school administration had noted several children in these grades who exhibited internalizing behavior such as social withdrawal and isolation. Because these grades included students with internalizing symptoms, we were able to observe solitary behavior and note effects of the intervention. Kindergarten recess was not included because it was on a different schedule and on a separate enclosed playground. A total of 21 teachers were involved in this study: 20 were female, 20 were Caucasian and one was Hispanic. The school principal, a female Caucasian educator with 21 years of experience (four years as a principal), also participated. The principal investigator, a graduate student in school psychology supervised by a university faculty member, trained observers and general education teachers in all aspects of the intervention. Four undergraduate university students served as data observers. These students were studying psychology, education, or a related field.

Two playgrounds were observed at the school. The playground for Grades 4 to 6 included a large square area in which students were free to roam during the recess period. The south half of this playground contained a large grass field including an area for kickball/softball and an area to play football and soccer. On the northeast corner of the playground was a black topped surface and four basketball hoops. On the northwest corner of the playground was a structure consisting of monkey bars, slides and climbing equipment. The playground for Grades 1-3 was located on the opposite side of the school. This playground was also located in a square area where students were free to roam during their recess. The southwest corner of this playground contained monkey bars, slides, climbing equipment, and a swing set. The southeast portion of the playground contained a large blacktopped area that was typically used for playing basketball and jump rope. The northern half of the playground included a large grass field with areas to play football and soccer. Students were not permitted to leave these areas during the recess period; two teachers at the school supervised recess each day. All teachers in the school participated in a rotation and each had an opportunity to supervise recess while the buddy bench was in use.

\section{Intervention and Materials}

The intervention in this study consisted of the placement of buddy benches at prominent locations on the school playgrounds (so students could easily locate the bench and observers could position themselves within earshot of the bench). Teachers instructed classes on how to use the bench including the use of a student involved roleplay, with rules posted in every classroom in the school and a daily school-wide announcement by the principal reminding students to use the bench as listed in the rules. Instruction took place over one day and took less than 10 minutes to complete. The posted buddy bench rules were as follows:

\section{If you are alone}

1. Sit at the buddy bench.

2. If someone invites you to play with them, say "yes" or "no, thank you."

If you see someone who is alone at the bench

1. Join them and invite them to play, talk or walk with you.

2. If they say "no," say "okay, maybe next time," and walk away.

This study required two benches made of durable metal and plastic material with a colorful design, each 6 feet long, labeled "buddy bench." These benches were portable, though heavy enough that the children could not easily move them. School staff removed the benches 
at the end of each school day and replaced them the following morning during intervention phases. Benches were purchased with research funds and donated to the school.

\section{Measures}

We collected three measures in this study: treatment fidelity data, the number of students engaged in solitary behavior, and social validity surveys.

Treatment fidelity. Teachers self-reported that they had taught students the buddy bench rules using the teaching script, posted the buddy bench rules, and explained the intervention as directed. Observers also verified that teachers had posted the buddy bench rules in their classrooms. The school principal tracked and selfreported days she had made the school-wide announcement reminding students to use the bench as directed, and then reported this data to the researchers.

Four direct observation measures of treatment fidelity were also collected to assess whether students were using the buddy bench as instructed. First, observers recorded the number of students using the bench (sitting at or leaning on it) during each observation period. A student sitting on the ground or standing near the bench was not considered to be using it.

Second, observers recorded the number of play invitations extended to students using the bench. If a student joined another student sitting at the bench and invited that student to play, this was considered an invitation. If a student walked near the bench and interacted with a student sitting at the bench and invited him to play, this also was considered an invitation. If a student or group of students were playing near the bench and the student at the bench decided to play with them of his own accord, this was not considered an invitation extended to the student.

Third, observers recorded the number of play invitations accepted by students using the buddy bench. If a student sitting at the bench was asked by another student to play, showed some form of acknowledgement/acceptance, and left with the student or group to play, this was considered a play invitation accepted. If a student sitting at the bench declined the invitation, this was not considered a play invitation accepted.

Finally, observers recorded successful teacher-directed prompts if they observed a teacher verbally prompt a student and then observed the student using the bench. If a student received direction to sit at the bench and did so, this was a successful teacher-directed prompt. If a student received direction to use the bench but did not do so, this was not a successful teacher-directed prompt.

Number of students engaged in solitary behavior. The dependent variable was the number of students engaged in solitary behavior graphed as an average per observation interval. Observers scanned the playground area for 20-second intervals (with 10-second recording periods between intervals) and used partial-interval recording of the number of students engaging in any type of solitary behavior. Solitary behavior was defined as not being engaged with other students or engaging in behavior alone with no other students within five feet. If a student was sitting or standing alone, solitary behavior was recorded. If a student was standing alone but throwing a football with another student more than five feet away, solitary behavior was not considered. All observers compiled data by observing the playground for five-minute intervals, with the daily average calculated for comparison across conditions. Observers sufficiently matched above $80 \%$ interrater reliability with a second observer who independently collected data for approximately $50 \%$ of data collection sessions. Agreement was calculated by dividing the smaller total by the larger total and multiplying by 100 to obtain an interobserver agreement percentage. The average interobserver agreement across all observations was $87.97 \%$.

Social validity surveys. The school principal distributed an anonymous post-intervention social validity survey to all students and teachers to assess how participants viewed the intervention. Surveys were adapted from those used by Teerlink et al. (2016); they contained seven questions and took participants less than 10 minutes to complete. All responses were coded on a five-point Likert scale, ranging from strongly disagree to strongly agree. A space was provided for participants to make comments regarding aspects of the intervention that they liked or disliked.

\section{Experimental Design and Procedures}

This study was conducted over approximately 10 weeks using a multiple baseline across participants design (Cooper, Heron, \& Heward, 2007), with a withdrawal phase added on one playground to confirm the controlling effects of the intervention. The playground for Grades 4 to 6 was exposed to two conditions: baseline and intervention. The playground for Grades 1 to 3 was exposed to four conditions: (a) baseline, (b) intervention, (c) withdrawal, and (d) return to intervention. Observations occurred daily at noon during a 15-minute lunch recess period.

Baseline. To establish a baseline, we observed the playgrounds with no changes other than the presence of observers. The buddy bench had not yet been installed on each playground, and teachers had not yet instructed students on what to do with it. Before the data collection, observers were present during the recess period to help students become accustomed to their presence. We collected baseline data on each playground for at least 13 days before moving to the intervention condition.

Training. After baseline, the principal investigator instructed 1st to 3rd teachers to post the buddy bench rules and explain to their classes that the bench was where students could go if they felt lonely or wanted to make a friend. Teachers were instructed to tell their students that if they saw someone sitting at the bench they should follow the posted buddy bench rules (e.g., either sit with this peer and engage in conversation or ask the peer to join them in playground activities). Teachers included a short role-play as a model for students. Students were informed that teachers on recess duty 
would prompt students engaged in solitary behavior to use the bench.

Intervention. Following training school staff placed the buddy bench on the 1 st to 3 rd recess playground. The school principal also began making morning announcements for these grades to use the bench and follow the posted rules. We collected data for 16 days before similarly training the second group of teachers and starting the intervention on the 4 th to 6 th grade playground, where we collected for 10 days.

Withdrawal. During the withdrawal phase, school staff removed the buddy bench from the 1 st to 3rd grade playground, and those students were informed by their teachers and during the morning announcement that their bench would not be used; teachers no longer prompted students to befriend students who were alone. After a visible trend was observed ( 6 days), we initiated a final "return to intervention" phase. A withdrawal phase was not included on the 4th to 6th grade playground due to the school year ending.

Return to intervention. During the return to intervention phase, the buddy bench was returned to the 1st to $3 \mathrm{rd}$ playground and students were again prompted to use the bench during morning announcements and by recess supervisors. We collected data in this phase (3 days) just before the conclusion of the school year.

\section{Data Analysis}

We used descriptive statistics to analyze treatment fidelity data. We graphed dependent variable data (the average daily number of students engaged in solitary behavior) to provide a visual representation of results, which we analyzed for changes in level, trend, and variability to determine the effectiveness of the intervention. Tau-U, a nonparametric effect size statistic appropriate for singlesubject research that analyzes non-overlapping data points between different phases (Parker, Vannest, Davis, \& Sauber, 2011), was also calculated using an online calculator (www.singlecaseresearch.org/calculators/tauu). Rakap (2015) recommends interpreting Tau-U effect sizes of less than 0.65 as small, 0.66 to 0.92 as medium, and greater than 0.92 as large. Each playground's baseline data were contrasted with the first intervention phase data, and reversal data were contrasted with the second intervention phase data.

Social validity data were analyzed using descriptive statistics (of Likert ratings) and qualitative coding (of written comments). The percentage of respondents who agreed or strongly agreed with each statement on the survey was calculated. Written comments were analyzed, similar to Teerlink et al. (2016). First, we analyzed, organized, and coded statements from students and teachers by grouping responses associated with approval or disapproval of the buddy bench. Next, we grouped common themes and calculated the number of participants whose comments fit each theme.

\section{Results}

\section{Treatment Fidelity}

Direct observations verified that the bench was present on the playground during $100 \%$ of the intervention phases. All teachers reported that they had instructed their classes on how to use the buddy bench. Observers noted that the buddy bench rules were posted in all classrooms. The school principal reported that she announced the buddy bench rules and reminded the students to use the bench on $80 \%$ of intervention days, but neglected to do so for $20 \%$ of intervention days. Students on the 1st to 3rd grade playground extended 130 invitations to students using the bench throughout all intervention phases, of which 76 (58\%) were accepted and led to play activities. At any given time during intervention phases, on average $1.03(S D=.64)$ students were using the bench. Teacher prompts to use the bench or invite someone to play accounted for only six uses of the bench during the intervention phases on the 1st to 3rd grade playground. Students on the 4 th to 6 th grade playground extended 75 invitations to students using the bench throughout all intervention phases, of which 47 (63\%) were accepted and led to play activities. At any given time during intervention phases, the average number of students using the bench was .8 (SD= .70). Teacher prompts to use the bench or invite someone to play accounted for only two bench uses during the intervention phase on the 4th to 6th grade playground.

\section{Effects on Solitary Behavior}

This section describes the average number of solitary students on the playground across phases of the study. The daily average during baseline was $4.84(\mathrm{SD}=0.93)$ solitary students on the 1 st to 3 rd grade playground and $3.47(S D=.78)$ solitary students on the 4th to 6 th grade playground. Data points were variable on both playgrounds with stable trends (see Figure 1).

The daily average during intervention decreased to 3.64 solitary students $(S D=.96)$ on the 1 st to 3rd grade playground, a $24 \%$ reduction from baseline with an immediate effect evident when the bench was introduced. The effect size from baseline to intervention was found to be statistically significant and small (Tau- $U=-.59, p<.001)$. The daily average decreased to $2.76(S D=.80)$ during intervention on the 4 th to 6 th grade playground, a $19 \%$ reduction from baseline with a gradual effect. As with the first playground, the effect size from baseline to intervention was statistically significant and small (Tau- $U=$ $-.51, p<.001$ ). Data points on each playground during this phase were variable with stable trends (see Figure 1).

When the Buddy Bench was removed from the first playground, data gradually returned to near baseline levels of 4.13 solitary students $(S D=1.11)$, a $13 \%$ increase from the intervention phase. The effect size from intervention to withdrawal was not found to be statistically significant (Tau- $U=-.28, p=0.12$ ), but data displayed a moderate upward trend.

When the Buddy Bench was returned to the playground, the daily average of students engaged in solitary behavior immediately decreased to near initial intervention levels 
of 3.74, $(\mathrm{SD}=.83)$, a $13 \%$ decrease from withdrawal. The effect size from withdrawal to intervention was found to be small and close to statistical significance (Tau- $U=-.58$, $p=0.06$ ). Data displayed a variable stable trend.

\section{Social Validity}

The social validity survey was completed by 347 (89.43\%) of the student participants and $15(71.43 \%)$ of the teacher participants. The percentage agreeing with each social validity item is listed in Table 1 . Students had primarily positive perceptions of the intervention, with the majority (73.26\%) agreeing that the bench helped students make more friends, was a good idea for their playground $(68.80 \%)$ and that they wanted the bench used at their school again next year (60.88\%). However, less than half (41.94\%) said they liked using the bench at recess. When responses were compared across playgrounds, results indicated higher approval from younger students. On average, students on the 1st to 3rd grade playground (172 responses) gave higher approval ratings to the intervention ( 4.25 out of 5), while students on the 4 th to 6th grade playground ( 175 responses) were less favorable (2.94 out of 5). Students' qualitative responses included a range of reactions:

- "It's a great idea!"

- " "It helped kids who were hurt inside."

- "I made new friends."

- "If you are lonely you can sit on it, but I think it only works on the lower grades."

- "People make fun of people on the bench."

- " "I am so sad that I am a new kid."

- "It was introduced too late in the year, everyone already had cliques."

- "People sometimes said no to everyone."

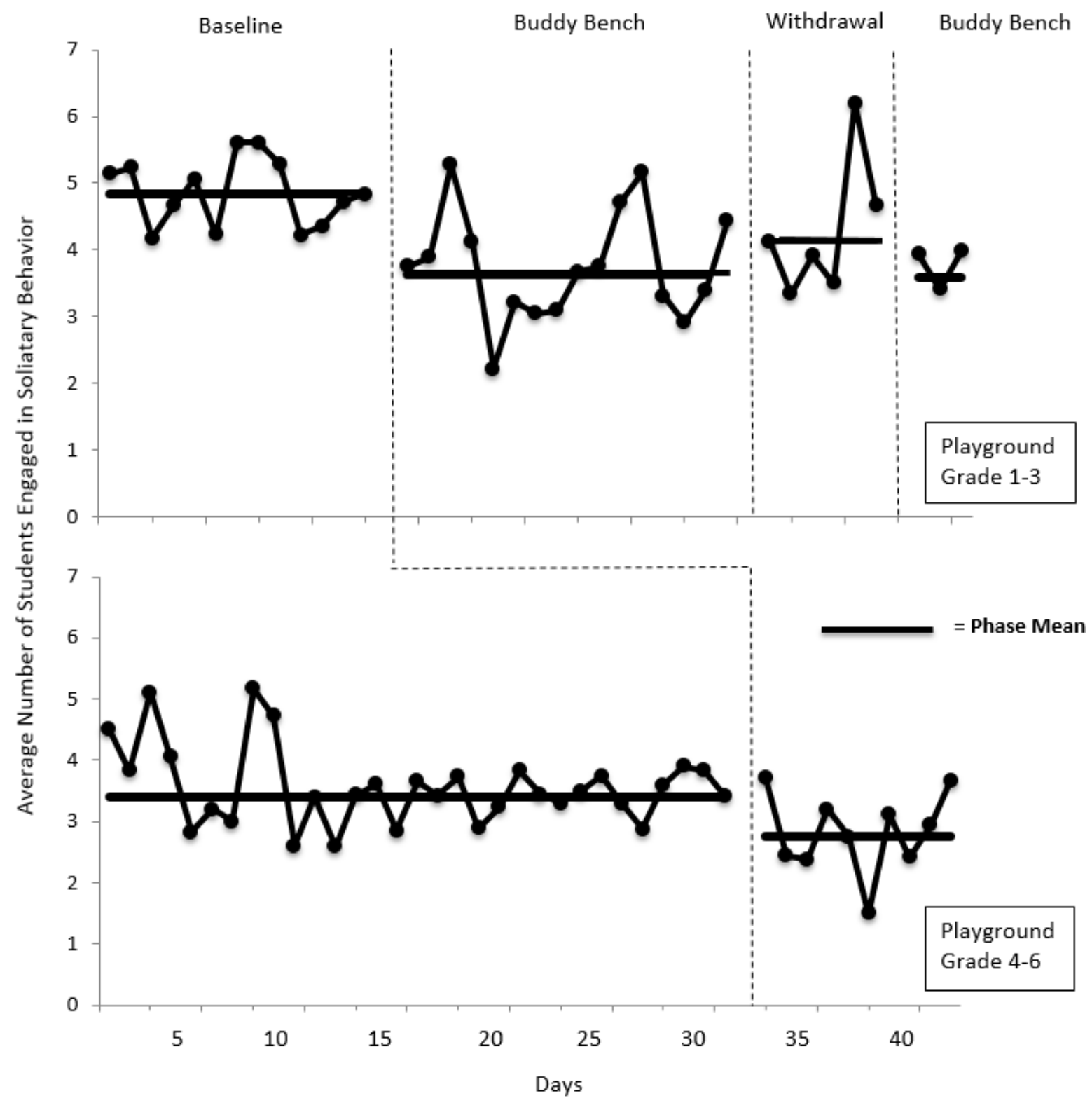

Figure 1. Multiple baseline comparison across playgrounds showing the average number of students engaged in solitary behavior per 15 minute lunch recess periods during baseline and treatment conditions. 
Table 1. Percentage of Participants Who Agreed on Buddy Bench Social Validity Survey Items

\begin{tabular}{lr}
\hline & $\begin{array}{r}\% \text { of } \\
\text { Student Rating Items }\end{array}$ \\
& $\begin{array}{r}\text { Students } \\
(n=347)\end{array}$ \\
\hline The buddy bench helped students at my school make more friends. & 73.26 \\
I thought the buddy bench was a good idea for our playground. & 68.80 \\
If I felt lonely I would use the buddy bench. & 63.85 \\
I want to have the buddy bench at my school next year. & 60.88 \\
The buddy bench helped me get along better with my peers. & 47.68 \\
The buddy bench helped me talk to new friends. & 46.81 \\
I liked using the buddy bench at recess. & 41.94 \\
\hline & $\%$ of \\
Teacher Rating Items & Teachers \\
& $(n=15)$ \\
\hline Peer interaction increased as a result of the buddy bench. & 66.67 \\
Students sitting at the bench were consistently befriended and invited to play by their peers. & 60.00 \\
Students liked using the buddy bench. & 60.00 \\
Fewer students spent recess alone as a result of the buddy bench. & 57.15 \\
I want the buddy bench on the school playground next year. & 53.33 \\
Students made more friends as a result of the buddy bench. & 46.66 \\
The buddy bench helped students improve their playground behavior. & 13.34 \\
\hline
\end{tabular}

The most common positive qualitative response from students was that the buddy bench "helped me make more friends" (125 responses) and "it helped other students" (66 responses). The most common negative responses were that students "misused it or didn't follow the rules" (52 responses) and "it didn't work in helping people make new friends" (19 responses). Some noted that they were never asked to play while on the bench (12 responses) and that sometimes teasing was directed towards those using the bench (10 responses).

Teachers were highest percentage of agreement was with the statement that peer interaction increased as a result of the bench (66.67\%). The majority (60.00\%) agreed that students were consistently befriended while at the bench, that students liked the bench $(60.00 \%)$, that fewer students spent recess alone (57.15\%), and that they wanted the bench to be used at their school the following year $(53.33 \%)$. However, only $13.34 \%$ of teachers surveyed agreed that the bench helped improve student behavior on the playground. The most common positive qualitative response was that the bench was helpful in fostering friendships or provided an additional way to make friends on the playground ( 6 responses). The most common negative response was that students misused the bench (7 responses). Some of the positive responses called attention to specific benefits of the intervention.

- "It gave students a clear course of action if they needed a friend."

- "It gave students an opportunity to make friends in a less intimidating way."

- "It called attention to children that there are lonely children. They became more aware."

Some notable negative responses showed that students' attitudes and behavior around the buddy bench were sometimes not what had been intended.
- "Many students misused the bench. They played on it or made fun of people there."

- "Students who never had problems finding a friend were all of the sudden loners just so they could use the bench."

- "Some students sat there to get attention and then would not play when asked by others to play."

\section{Discussion}

This is the first observational study to document the effects of a buddy bench intervention on student behavior. Treatment fidelity results suggest that the buddy bench intervention was generally implemented as designed. The bench was always present during intervention phases, as verified by direct observations. All teachers reported that they had taught students to use the bench and observers noted posted buddy bench rules in their classrooms. The school principal reported that she had made the daily announcement reminding students to use the bench as directed on $80 \%$ of intervention days. Combining results for the two playgrounds, during the intervention 205 invitations were extended to students when they were at the bench, the majority of which led to a play activity. However, the intervention may have been more effective had teachers been more proactive in prompting solitary students to use it. Observers noted that typically only two teachers supervised recess and they were often too preoccupied with other activities (e.g., talking to groups of students or other teachers or distributing balls and play equipment) to seek out solitary students to prompt to use the bench. Teerlink et al. (2016) experienced similar problems with recess supervisors participating in their recess intervention. Teerlink and colleagues suggested that urging recess supervisors to take a more active role in the intervention by informing them of daily goals, specifying students to look out for, and passing on daily information 
on the progress of the intervention might help them become more personally involved in the intervention. We think these same recommendations apply to the buddy bench intervention.

Results of changes in student solitary behavior across baseline and intervention phases suggested a potentially functional relationship, although significant treatment effects were found only twice: the initial changes from baseline to intervention phases across both playgrounds (Kratochwill et al., 2010). While the withdrawal and return to intervention phases appeared to have a similar effect, these were not determined to be statistically significant as students may have used the bench to make new friends during the first intervention phases yielding a therapuetic effect (Onwuebgbuzie, 2003).

In terms of social validity results, almost three-fourths of students agreed that the buddy bench helped students make friends. The majority of students agreed that if they felt lonely they would use the bench, that the bench was a good idea for their school, and that they wanted the bench at their school the following year. However, less than half agreed that the bench helped them personally or that they enjoyed using the bench themselves. It appears that while students liked the idea of a buddy bench at their school, many may have thought of it as an intervention to help other students and not necessarily themselves. Teachers appeared split on their perceptions of the intervention: Approximately half agreed that they wanted to use the bench the following year and that students made more friends as a result of the bench. The majority also agreed that students liked the buddy bench, peer interactions at recess increased, fewer students spent recess alone, and students using the bench were consistently befriended and invited to play. However, only $13 \%$ agreed that the bench helped students improve their playground behavior. The purpose of this intervention was aimed at solitary behavior rather than problem behavior, so this may explain the lower rating by teachers. It is also relevant to mention that on many social validity survey items the most common response from teachers was not sure/neutral. Perhaps with a longer exposure period and greater involvement teachers might have decided more strongly for or against this intervention. Similar to the results of Teerlink et al. (2016), students' social validity ratings of the intervention were higher than teachers' ratings. Students were the individuals most involved in using the buddy bench; having less investment in the intervention might have affected teachers' social validity ratings.

As mentioned earlier, media outlets have documented the spread of buddy benches across schools in the United States. In our study students' perceptions of the buddy bench were largely positive, but teachers' reactions were more neutral. However, media coverage has reported almost exclusively positive perceptions of the buddy bench (Itkowitz, 2016; Mansoor, 2016). Perhaps media coverage of the intervention includes only positive comments or interviews with school personnel who are more removed from the intervention than teachers who oversee recess, like those surveyed in our study. The intervention may have also been implemented differently in schools reported in the media, resulting in greater success or more satisfaction among stakeholders. The Associated Press (2013) reported that Christian Bucks, the student who introduced the idea in his school in Pennsylvania, said that the buddy bench helped create an atmosphere that encouraged befriending others. Christian's mother, Alyson Bucks, noted, "It was the Roundtown (school) faculty and staff who brought the idea to fruition" (Associated Press, p. 1), highlighting staff buy-in and participation as key elements to success.

We believe the buddy bench was successful in that it served as (a) a discriminative stimulus, which preceded rule-following behavior (e.g., inviting others to interact, join play activities), and (b) a reinforcement by giving students a place to gather should they feel intimidated when seeking out play activities on their own (Cooper et al., 2007). Antecedent events (seeing the bench, or seeing students at the bench) increased the likelihood that students would either use the bench or invite those at the bench to play. Using the bench was reinforced by social interaction, following rules, and being asked to play or making a new friend. As a result, students learned to use the behavior of asking others to play or sitting at the bench when the discriminative stimulus of the bench was present.

\section{Limitations and Future Directions}

This study had several limitations. First, it took place at one urban Title 1 elementary school in central Utah with a large percentage of minority students, primarily Hispanic. Future studies should test the intervention with other schools, including varied SES and grade levels, and examining effects at more than one school. We only collected self-reports of teachers instructing students to use the bench and of the school principal making morning announcements about the bench. Future studies would benefit from collecting direct observations of these fidelity components. Our teacher prompting aspect was implemented with low fidelity and might have resulted in greater change in student solitary behavior if prompting had been utilized more fully. Future studies would benefit from teachers more actively monitoring students' proper use of the bench.

While results suggest that approximately one student per playground was no longer engaged in solitary behavior when the intervention was being used, we were unable to identify if this was the same student or if different students were engaging or no longer engaging in solitary behavior. We could have adopted a different focus and studied each student individually. Using a method similar to Coplan, Ooi, Rose-Krasnor, and Nocita (2014) could have also been valuable in assessing function and designing individual interventions. Furthermore, in terms of social validity data, less than half of the students endorsed that they enjoyed using the bench, however, we did not collect data on which individual students used the bench. In retrospect, we should have included a social validity survey item asking students whether they used the bench at least once during the course of the study to better understand their responses. Future studies would benefit from studying the effects of the buddy bench intervention on specific solitary students. 
Finally, because the intervention began later into the school year, we were only able to complete a reversal and return to intervention phase on one playground. While the results were encouraging, our research design was somewhat limited in that the withdrawal and return to intervention phases on this playground did not yield statistically significant results, though they were very near significance (i.e., $p=.06$ ). As mentioned earlier, there was possibly a therapeutic effect, as students who were making friends during the intervention phase may no longer have needed to use the bench once the withdrawal phase began. Future research would benefit from starting earlier in the school year and conducting reversal designs on more than one playground.

\section{Conclusion}

SWPBS is aimed at improving the learning environment in schools by fostering positive social interactions and addressing students' emotional and behavioral concerns (Lewis \& Sugai 1999; Young et al., 2011). The use of simple, cost-effective SWPBS strategies to proactively manage student behavior and improve student outcomes is also emphasized (Cook et al., 2017). Given the need to address internalizing behaviors at recess, the buddy bench intervention shows promise as a relatively simple strategy to improve the school recess environment. Study findings suggest that the buddy bench intervention was socially valid, economical, and helped students decrease their social isolation and engage in more social interactions at recess. Future research is needed to confirm the positive effects found in the present study.

\section{References}

Arthur, L. (2004). Looking out for each other: Children helping left out children. Support for Learning, 19, 512. doi:10.1111/j.0268-2141.2004.00311.x

Associated Press. (2013, December 14). Boy creates "buddy

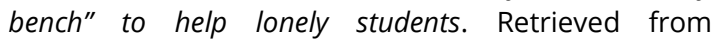
http://www.nbcphiladelphia.com/news/local/BoyCreates-Buddy-Bench-to-Help-Lonely-Students234528981.html

Bleeker, M., James-Burdumy, S., Beyler, N., Dodd, A. H., London, R. A., Westrich, L., \& Castrechini, S. (2012). Findings from a randomized experiment of Playworks: Selected results from cohort. Princeton, NJ: Mathematica Policy Research.

Brumariu, L. E. (2010). Mother-child attachment in early childhood and anxiety symptoms in preadolescence: The role of peer competence and emotion regulation (Unpublished doctoral dissertation). Kent State University, Kent, $\mathrm{OH}$.

Cook, C. R., Grady, E. A., Long, A. C., Renshaw, T., Codding, R. S., Fiat, A., \& Larson, M. (2017). Evaluating the impact of increasing general education teachers' ratio of positive-to-negative interactions on students' classroom behavior. Journal of Positive Behavior Interventions, $19, \quad 67-77$. doi:10.1177/1098300716679137
Cooper, J. O., Heron, T. T., \& Heward, W. L. (2007). Applied behavior analysis (2nd ed.). Upper Saddle River, NJ: Pearson, Merrill, Prentice Hall.

Coplan, R. J., Ooi, L. L., \& Rose-Krasnor, L. (2015). Naturalistic observations of schoolyard social participation marker variables for socio-emotional functioning in early adolescence. The Journal of Early Adolescence, 35,

628-650. doi:10.1177/0272431614523134

Coplan, R. J., Ooi, L. L., Rose-Krasnor, L., \& Nocita, G. (2014). "I want to play alone": Assessment and correlates of self-reported preference for solitary play in young children. Infant and Child Development, 23, 229-238. doi:10.1002/icd.1854

Coplan, R. J., Rose-Krasnor, L., Weeks, M., Kingsbury, A., Kingsbury, M., \& Bullock, A. (2013). Alone is a crowd: Social motivations, social withdrawal, and socioemotional functioning in later childhood. Developmental Psychology, 49, 861-875. doi:10.1037/a0028861

Fergusson, D. M., \& Woodward, L. J. (2002). Mental health, educational, and social role outcomes of adolescents with depression. Archivs of General Psychiatry, 59, 225231. doi:10.1001/archpsyc.59.3.225

Franzen, K., \& Kamps, D. (2008). The utilization and effects of positive behavior support strategies on an urban school playground. Journal of Positive Behavior Interventions, 10 , 150-161. doi:10.1177/1098300708316260

Gage, N. A. (2013). Characteristics of students with emotional disturbance manifesting internalizing behaviors: A latent class analysis. Education and Treatment of Children, 36, 127-145. doi:10.1353/etc.2013.0038

Ginsburg, K. R. (2007). The importance of play in promoting healthy child development and maintaining strong parent-child bonds. Pediatrics, 119, 182-191. doi:10.1542/peds.2006-2697

Gresham, F. M., \& Kern, L. (2004). Internalizing behavior problems in children and adolescents. In R. B. Rutherford, M. M. Quinn, \& S. R. Mathur (Eds.), Handbook of research in emotional and behavioral disorders (pp. 262-281). New York, NY: Guilford Press.

Itkowitz, C. (2016, April 4). Kids don't have to be lonely at recess anymore thanks to this little boy and his "buddy bench." The Washington Post. Retrieved from http://www.washingtonpost.com

Jennings, J. H., Caldwell, J. S., \& Lerner, J. W. (2013). Reading problems: Assessment and teaching strategies. Boston, MA: Pearson Higher Ed.

Jorgensen, T. (2015, October 18). More Utah students suggest playground "buddy" benches for their schools. KSL News. Retrieved from http://www.KSL.com

Kamps, D., Wills, H. P., Heitzman-Powell, L., Laylin, J., Szoke, C., Petrillo, T., \& Culey, A. (2011). Class-wide 
function-related intervention teams: Effects of group contingency programs in urban classrooms. Journal of Positive Behavior Interventions, 13, 154-167. doi:10.1177/1098300711398935

Kauffman, J. M. (2001). Characteristics of emotional and behavioral disorders of children and youth (7th ed.). Columbus, $\mathrm{OH}$ : Merrill.

Kratochwill, T. R., Hitchcock, J., Horner, R. H., Levin, J. R., Odom, S. L., Rindskopf, D. M., \& Shadish, W. R. (2010). Single-case designs technical documentation. Retrieved from https://eric.ed.gov/?id=ED510743

Lane, K. L., Barton-Arwood, S. M., Nelson, J. R., \& Wehby, J. (2008). Academic performance of students with emotional and behavioral disorders served in a selfcontained setting. Journal of Behavioral Education, 17, 43-62. doi:10.1007/s10864-007-9050-1

Lewis, T. J., \& Sugai, G. (1999). Effective behavior support: A systems approach to proactive schoolwide management. Focus on Exceptional Children, 31(6), 124.

Mansoor, S. (2016, September 30). Buddy benches help fight loneliness on the playground. The Dallas Morning News. Retrieved from http://www.dallasnews.com

Marchant, M. R., Solano, B. R., Fisher, A. K., Caldarella, P., Young, K. R., \& Renshaw, T. L. (2007). Modifying socially withdrawn behavior: A playground intervention for students with internalizing behaviors. Psychology in the Schools, 44, 779-794. doi:10.1002/pits.20265

McCall, Z. A. (2011). Predictors of post-school outcomes for students with emotional or behavioral disabilities: Racelethnicity, family income, gender, and student and family engagement (Unpublished doctoral dissertation). University of Kansas, Lawrence, KS.

McClintick-Greene, H. A. (2012). College bound: Examining the adequacy of high school transition planning for youth with internalizing disorders. lowa Research Online, University of lowa. Retrieved from http://ir.uiowa.edu/etd/3349

Merrell, K. W., \& Gimpel, G. A. (1998). Social skills of children and adolescents: Conceptualization, assessment, treatment. Mahwah, NJ: Lawrence Erlbaum Associates.

Morris, R. J., Shah, K., \& Morris, Y. P. (2002). Internalizing behavior disorders. In K. Lane, F. Gresham, \& T.
O'Shaughnessy (Eds.), Interventions for children with or at risk for emotional and behavioral disorders (pp. 223241). Boston, MA: Allyn \& Bacon.

Onwuegbuzie, A. J. (2003). Expanding the framework of internal and external validity in quantitative research. Research in the Schools, 10, 71-90.

Parker, R. I., Vannest, K. J., Davis, J. L., \& Sauber, S. B. (2011). Combining nonoverlap and trend for singlecase research: Tau-U. Behavior Therapy, 42, 284299. doi.org/10.1016/j.beth.2010.08.006

Pellegrini, A. D., \& Bohn, C. M. (2005). The role of recess in children's cognitive performance and school adjustment. Educational Researcher, 34, 13-19. doi:10.3102/0013189X034001013

Rakap, S. (2015). Effect sizes as result interpretation aids in single-subject experimental research: Description and application of four nonoverlap methods. British Journal of Special Education, 42, 1133. doi:10.1111/1467-8578.12091

Rubin, K. H., \& Coplan, R. J. (2004). Paying attention to and not neglecting social withdrawal and social isolation. Merrill-Palmer Quarterly, 50, 506-534. doi:10.1353/mpq.2004.0036

Sugai, G., \& Horner, R. R. (2006). A promising approach for expanding and sustaining school-wide positive behavior support. School Psychology Review, 35, 245259.

Teerlink, E. A., Caldarella, P., Anderson, D. H., Richardson, M. J., \& Guzman, G. (2017). Addressing problem behavior at recess using peer praise notes. Journal of Positive Behavior Interventions, 19, 115-126. doi: 10.1177/1098300716675733

Wagner, M., Newman, L., Cameto, R., \& Levine, P. (2005). Changes over time in the early postschool outcomes of youth with disabilities. A report of findings from the National Longitudinal Transition Study (NLTS) and the National Longitudinal Transition Study-2 (NLTS2). Menlo Park, CA: SRI International. Retrieved from www.nlts2.org/reports/ 2005 06/nlts2 report 200506 complete.pdf

Young, E. L., Caldarella, P., Richardson, M. J., \& Young, K. (2011). Positive behavior support in secondary schools: A practical guide. New York, NY: Guilford Press. 